\title{
Phase change humidity control material and its impact on building energy consumption
}

\author{
Wu, Zhimin; Qin, Menghao; Zhang, Mingjie
}

Published in:

Energy and Buildings

Link to article, DOI:

10.1016/j.enbuild.2018.06.036

Publication date:

2018

Document Version

Peer reviewed version

Link back to DTU Orbit

Citation (APA):

Wu, Z., Qin, M., \& Zhang, M. (2018). Phase change humidity control material and its impact on building energy consumption. Energy and Buildings, 174, 254-261. https://doi.org/10.1016/j.enbuild.2018.06.036

\section{General rights}

Copyright and moral rights for the publications made accessible in the public portal are retained by the authors and/or other copyright owners and it is a condition of accessing publications that users recognise and abide by the legal requirements associated with these rights.

- Users may download and print one copy of any publication from the public portal for the purpose of private study or research.

- You may not further distribute the material or use it for any profit-making activity or commercial gain

- You may freely distribute the URL identifying the publication in the public portal 


\section{Accepted Manuscript}

Phase change humidity control material and its impact on building energy consumption

Zhimin Wu, Menghao Qin, Mingjie Zhang

PII:

DOI:

Reference:

$$
\text { S0378-7788(18)30810-7 }
$$

10.1016/j.enbuild.2018.06.036

ENB 8638

To appear in:

Received date:

Revised date:

Accepted date:

\section{Energy \& Buildings}

11 March 2018

1 May 2018

17 June 2018

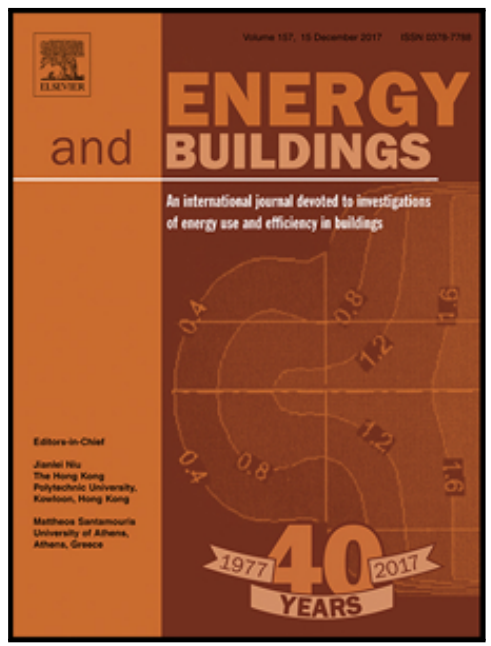

Please cite this article as: Zhimin Wu, Menghao Qin, Mingjie Zhang, Phase change humidity control material and its impact on building energy consumption, Energy \& Buildings (2018), doi: 10.1016/j.enbuild.2018.06.036

This is a PDF file of an unedited manuscript that has been accepted for publication. As a service to our customers we are providing this early version of the manuscript. The manuscript will undergo copyediting, typesetting, and review of the resulting proof before it is published in its final form. Please note that during the production process errors may be discovered which could affect the content, and all legal disclaimers that apply to the journal pertain. 


\section{Highlights}

- The PCHCM could moderate both indoor temperature and relative humidity simultaneously.

- A combined HAMT and enthalpy model is developed to evaluate the performance of PCHCM.

- The PCHCM has a great impact on the energy performance of buildings.

- The potential energy saving by using PCHCM could up to $20 \%$. 


\title{
Phase change humidity control material and its impact on building energy consumption
}

\author{
Zhimin $\mathrm{Wu}^{1}$, Menghao Qin ${ }^{2 *}$, Mingjie Zhang $^{1}$ \\ ${ }^{1}$ School of Architecture and Urban Planning, Nanjing University, Nanjing, China \\ ${ }^{2}$ Department of Civil Engineering, Technical University of Demark (DTU), \\ Lyngby, Denmark
}

*Corresponding author: Dr Menghao Qin, Email address: menqin@byg.dtu.dk

\begin{abstract}
Phase change humidity control material (PCHCM) is a new kind of composite made of high performance phase change material (PCM) microcapsules and hygroscopic materials (e.g. diatomite etc.). The PCHCM composite can moderate the indoor hygrothermal conditions by absorbing or releasing both heat and moisture, and consequently effect the sensible and latent heat load of buildings. In this research, a novel model for analyzing the hygrothermal performance of the PCHCM in built environment is developed and validated by experiments. The new model is then applied to investigate the impact of $\mathrm{PCHCM}$ on indoor hygrothermal conditions and building energy consumption in an office building under different climates (Beijing, Paris, Atlanta, and Guangzhou). The simulation results show that PCHCM has a great impact on the building energy performance in Paris and Atlanta climates, which have a large temperature and humidity difference between day and night. The maximal potential energy saving rate could be up to $19.57 \%$ in Paris. The model and analysis will provide a guidance for the application of PCHCM in different climate conditions.
\end{abstract}

\section{Keywords}

Phase change humidity control material, HAMT model, Enthalpy method, Hygrothermal performance, Energy saving simulation 


\section{Introduction}

In recent years, increased consumption of fossil fuels and excessive $\mathrm{CO}_{2}$ emissions have resulted in major environmental issues all over the world [1]. Evidence shows that building sector is responsible for $40 \%$ of global energy consumption and produces $30 \%$ of global greenhouse gas emissions annually [2]. The energy consumption of heating, ventilation and air-conditioning (HVAC) system in developed countries accounts for 50\% of the energy consumed in buildings [3]. Predictions indicate that global energy demand will increase by 50\% in 2030 [4]. For this reason, a reduction in HVAC system energy demand can significantly reduce the total energy consumption in buildings, which also contributes to the reduction of greenhouse gasses [5-6].

Indoor hygrothermal conditions should be controlled to maintain a healthy and comfortable environment by the HVAC system. In view of this, passive means (building envelope development) [7] are used to assist the active means (mechanical HVAC system) [8] to efficiently remove the indoor sensible and latent heat loads, and minimize the space heating/cooling energy consumption in buildings [9]. One promising approach is the application of innovative building materials, which can decrease the building energy consumption and control the indoor hygrothermal condition passively [10].

Building materials can moderate indoor temperature and humidity fluctuations. Phase change materials (PCM), which absorb or release large amount of thermal heat at a constant temperature in phase change process, can be used to moderate the indoor 
temperature variations and reduce the energy consumption of HVAC systems [11-13]. On the other hand, it is well known that indoor air humidity may have a significant influence on occupants' comfort and health in the living environment [14-15]. To maintain a stable and comfortable indoor relative humidity, HVAC system has been used to dehumidify/humidify the supply air from outdoor environment, which increases the air-conditioning loads. With the excellent moisture absorbing/releasing property, hygroscopic building materials can be used to moderate the indoor relative humidity variations and significantly reduce the peak/valley values of indoor relative humidity [16-19].

However, most building materials cannot simultaneously regulate the temperature and relative humidity of indoor air. Therefore, a novel passive material that has the capability of both thermal and moisture buffering is prepared in this paper. The synthesis of novel phase change humidity control material (PCHCM) was achieved by using composite microencapsulated phase change material (MPCM) and hygroscopic material. The MPCM was synthesized by the microencapsulated phase change material (PCM) with $\mathrm{SiO}_{2}$ shell [20] and the diatomite was used as hygroscopic material [21]. The PCHCM can moderate indoor air fluctuations of temperature and relative humidity by absorbing or releasing both heat and moisture with a better overall hygrothermal performance.

In the past decades, in order to evaluate the coupled heat and moisture transport behavior in porous building materials, one of the most used and accepted models for calculating heat and moisture transfer through porous media is the Luikov model [22] 
or Phillip and de Vries model [23]. However, to solve the problem of moisture content discontinuity, the relative humidity was used as a potential by Künzel [24]. Qin used the vapor content and temperature as principal driving potentials in a dynamic mathematical model, which can predict the coupled heat and moisture in multi-layer porous building materials $[25,26]$. On the other hand, Voller et al [27] proposed an enthalpy method that could be applied to a general convection/diffusion phase change process. Swaminathan et al. [28] derived a novel enthalpy method that include heat capacity and source based methods, thus an optimal enthalpy scheme was identified. However, very few models can be used to calculate the coupled heat, air and moisture transfer with phase change process.

The aim of the study presented in this paper consists of: (1) preparing a phase change humidity control material with better overall hygrothermal performance; (2) developing a dynamic mathematical model for evaluating the coupled heat, air and moisture transfer with phase change process; (3) studying the hygrothermal impact of applying the PCHCM in office buildings; and (4) analyzing the energy saving effect of PCHCM in different climate conditions.

\section{Preparation and characterization of PCHCM}

\subsection{Preparation of the PCHCM}

$2.5 \mathrm{~g}$ of sodium dodecyl sulfate and $20 \mathrm{~g}$ of PCM was dissolved into $100 \mathrm{ml}$ of distilled water in a beaker to form a mixed solution. The mixture was stirred at a rate 
of $600 \mathrm{rpm}$ for $0.5 \mathrm{~h}$ with a magnetic stirrer in a water bath at $35^{\circ} \mathrm{C}$. Then the mixture was stirred at $25^{\circ} \mathrm{C}$ for $0.5 \mathrm{~h}$.

$20 \mathrm{~g}$ of absolute ethanol, $20 \mathrm{~g}$ of methyl triethoxysilane and $30 \mathrm{ml}$ of distilled water were mixed into a beaker to prepare a mixed solution of MTES. The PH degree of the MTES mixed solution was adjusted to 2-3 by adding hydrochloric acid. Then the solution was stirred at a rate of $600 \mathrm{rpm}$ for $20 \mathrm{~min}$ at $50{ }^{\circ} \mathrm{C}$. Therefore, the sol solution with a large amount of $\mathrm{OH}-\mathrm{Si}-\mathrm{OH}$ groups was obtained by hydrolysis of the MTES. The PCM micro-emulsion was stirred at a rate of $400 \mathrm{rpm}$ at $35^{\circ} \mathrm{C}$ and the PH degree was adjusted to $9-10$ by adding ammonia solution. The sol solution with large amounts of $\mathrm{OH}-\mathrm{Si}-\mathrm{OH}$ groups was dropped into the PCM micro-emulsion in drops. The emulsion was kept being stirred reacting for $2 \mathrm{~h}$. Ultimately, the phase change microcapsules with $\mathrm{SiO}_{2}$ shell was collected by filter paper and placed in a vacuum oven with a constant temperature at $0^{\circ} \mathrm{C}$ for $24 \mathrm{~h}$ to obtain microencapsulated phase change material (MPCM).

The diatomite was placed in a vacuum oven at $100{ }^{\circ} \mathrm{C}$ for 10 hours to obtain a dried sample. And then $20 \mathrm{~g}$ of dried diatomite, $5 \mathrm{~g}$ of MPCM and $80 \mathrm{~g}$ of distilled water were mixed into a beaker to prepare a mixed solution. The mixed solution was stirred at a rate of $200 \mathrm{rpm}$ at room temperature for 5 min to prepare a brick-shaped test sample. The test sample was placed in a vacuum oven at $20^{\circ} \mathrm{C}$ for $48 \mathrm{~h}$ and the PCHCM was obtained. 


\subsection{Characterization of the PCHCM}

The PCHCM is composed of components including PCM and diatomite. The scanning electronic microscope (SEM) of MPCM and diatomite are presented in Fig.

1. The whole physical parameters of the PCHCM is listed in Table 1.
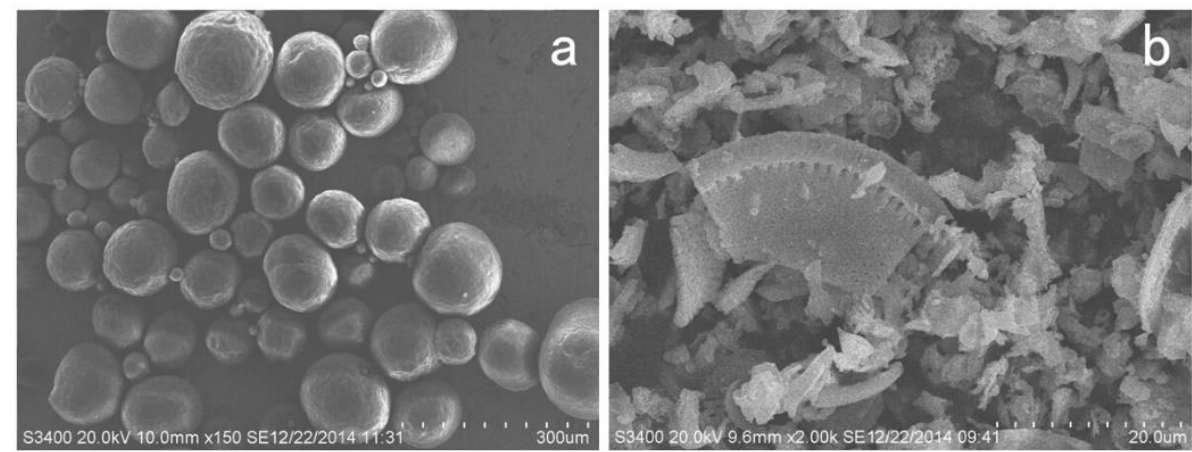

Fig. 1. SEM photographs of the MPCM (a) and diatomite (b)

The mass ratio of PCM component in PCHCM is $12.9 \%$, which contributes to the large storage capacity of latent heat in phase change process. The composition of PCM and diatomite enhance the overall physical performance. The higher moisture buffering value $\left(1.57 \mathrm{~g} / \mathrm{m}^{2} \% \mathrm{RH}\right)$ which belong to good class range [28] enable PCHCM display a better hygrothermal performance than the simple combination of two separate layers of PCM and hygroscopic materials (Table 2 and Table 3).

\section{Table 1}

Physical property parameters of PCHCM.

\begin{tabular}{|c|c|c|c|c|c|c|c|}
\hline Material & $\begin{array}{l}\text { Density } \\
\left(\mathrm{kg} \cdot \mathrm{m}^{-3}\right)\end{array}$ & $\begin{array}{l}\text { Thermal } \\
\text { Conductivity } \\
(\mathrm{W} / \mathrm{mK})\end{array}$ & $\begin{array}{l}\text { Phase change } \\
\text { latent heat } \\
(\mathrm{kJ} / \mathrm{kg})\end{array}$ & $\begin{array}{l}\text { Specific heat } \\
\text { capacity } \\
(\mathrm{J} / \mathrm{kgK})\end{array}$ & $\begin{array}{l}\text { Phase change } \\
\text { Temperature } \\
\text { range } \\
\left({ }^{\circ} \mathrm{C}\right)\end{array}$ & porosity & $\begin{array}{l}\mathrm{MBV} \\
\left(\mathrm{g} / \mathrm{m}^{2} \% \mathrm{RH}\right)\end{array}$ \\
\hline PCHCM & 650 & 0.85 & 18.4 & 975 & $25 \sim 27$ & 0.43 & 1.57 \\
\hline
\end{tabular}




\section{Table 2}

Thermal performance data of the PCM, MPCM and PCHCM.

\begin{tabular}{llll}
\hline Sample name & Encapsulation ratio of the PCM $(\%)$ & Melting $\left(5^{\circ} \mathrm{C} / \mathrm{min}\right)$ & Solidifying $\left(5^{\circ} \mathrm{C} / \mathrm{min}\right)$ \\
\cline { 3 - 4 } & & Latent heat $(\mathrm{kJ} / \mathrm{kg})$ & Latent heat $(\mathrm{kJ} / \mathrm{kg})$ \\
\hline PCM & 100.0 & 145.7 & 144.3 \\
MPCM & 63.4 & 94.4 & 89.6 \\
PCHCM & 12.9 & 19.0 & 18.4 \\
\hline
\end{tabular}

Table 3

Moisture performance data of the PCHCM, gypsum, wood and diatomite.

\begin{tabular}{lllll}
\hline Samples & PCHCM & Gypsum & Wood & Diatomite \\
\hline $\begin{array}{l}\text { Moisture transfer } \\
\text { coefficient }\left(10^{-8} \mathrm{~kg} / \mathrm{m} \mathrm{s}\right)\end{array}$ & 5.00 & 1.54 & 0.79 & 2.75 \\
$\mathrm{MBV} /\left(\mathrm{g} / \mathrm{m}^{2} \% \mathrm{RH}\right)$ & 1.57 & 0.26 & 0.40 & 0.33 \\
\hline
\end{tabular}

\section{Methodology}

\subsection{Coupled Heat and Moisture Transfer (HAMT) model}

The HAMT model which has high accuracy in computation can simulates the transport and storage of heat and moisture in building envelopes, as well as the simultaneous interaction with surrounded environment. Furthermore, the temperature and moisture profiles through composite building envelopes can be calculated to identify the hygrothermal conditions of building envelopes.

The following equations are taken from Künzel [24] which described the theoretical model of the coupled heat and moisture transfer through building envelopes. Equation (1) describes the heat balance of building envelops:

$$
\frac{\partial H_{\mathrm{wet}}}{\partial T} \frac{\partial T}{\partial t}=\frac{\partial}{\partial x}\left(k_{\omega} \frac{\partial T}{\partial x}\right)+h_{\mathrm{v}} \frac{\partial}{\partial x}\left(\frac{\delta}{\mu} \frac{\partial P_{\text {sat }}}{\partial x}\right)
$$

where $H_{\text {wet }}$ is the enthalpy of wet material $(\mathrm{kJ} / \mathrm{kg}), T$ is the temperature $(\mathrm{K}), t$ is the time (s), $x$ is the thickness $(\mathrm{m}), k_{\omega}$ is the heat conductivity coefficient $(\mathrm{W} / \mathrm{m} \cdot \mathrm{K}), h_{\mathrm{v}}$ is 
the vaporization enthalpy of water $(\mathrm{kJ} / \mathrm{kg}), \delta$ is the vapor diffusion coefficient in air $(\mathrm{kg} /(\mathrm{m} \cdot \mathrm{s} \cdot \mathrm{Pa})), \mu$ is the resistance coefficient of moisture, $P_{\text {sat }}$ is the partial pressure of saturated water vapor $(\mathrm{Pa})$.

The capacity of heat storage $\left(\frac{\partial H}{\partial T}\right)$ can be written as follows:

$\frac{\partial H_{\mathrm{wet}}}{\partial T}=c_{\mathrm{dry}} \rho_{\mathrm{dry}}+c^{\omega} \omega$

where $c_{\text {dry }}$ is the specific heat capacity of dry materials $(\mathrm{J} / \mathrm{kg} \cdot \mathrm{K}), \rho$ is the density of water $\left(\mathrm{kg} / \mathrm{m}^{3}\right), c^{\omega}$ is the specific heat capacity of liquid water $(\mathrm{J} / \mathrm{kg} \cdot \mathrm{K}), \omega$ is the water content $\left(\mathrm{kg} / \mathrm{m}^{3}\right)$.

Equation (3) describes the mass conservation of building envelops:

$\frac{\partial \omega}{\partial \varphi} \frac{\partial \varphi}{\partial t}=\frac{\partial}{\partial x}\left(D_{\omega} \frac{\partial \omega}{\partial \varphi} \frac{\partial \varphi}{\partial x}\right)+\frac{\partial}{\partial x}\left(\frac{\delta}{\mu} \frac{\partial P_{\text {sat }}}{\partial x}\right)$

where $\varphi$ is the relative humidity $(\%), D \omega$ is the transport coefficient of liquid $\left(\mathrm{m}^{2} / \mathrm{s}\right), \delta$ is the diffusion coefficient of air moisture $(\mathrm{kg} /(\mathrm{m} \cdot \mathrm{s} \cdot \mathrm{Pa}))$.

And the vapor diffusion coefficient in air $(\delta)$ can be expressed as:

$\delta=2 \times 10^{-7} \times \frac{T^{0.81}}{P_{\mathrm{amb}}}$

where $P_{\text {amb }}$ is the ambient air pressure $(\mathrm{Pa})$.

The left side of the Eqs. (1) and (3) are the heat/humidity storage terms. The heat/humidity fluxes on the right side depend on the interior and exterior climatic boundary conditions. Generally, the exterior boundary conditions of building zone are affected by exterior climate conditions. However, the interior boundary conditions are influenced by the following parameters, e.g. exterior climate conditions, humidity 
buffering of envelopes and furniture, HVAC system, internal moisture sources or sinks.

\subsection{Enthalpy method}

The enthalpy method can be used to calculate well with single point phase change materials $[27,30]$. The enthalpy $H$ could be split into sensible and latent heats. Additionally, the latent heat could be expressed as the melting fraction $f$ in one-dimensional transient heat equation as shown in Eq. (5) below,

$$
H_{\mathrm{dry}}=h+L f_{1}
$$

where $H_{\text {dry }}$ is the enthalpy of dry material $(\mathrm{kJ} / \mathrm{kg}), L$ is the latent enthalpy $(\mathrm{J} / \mathrm{kg}), f_{1}$ is the Liquid fraction, $\mathrm{h}$ is the sensible enthalpy $(\mathrm{J} / \mathrm{kg})$ and can be expressed as:

$$
h=\int_{T_{\mathrm{m}}}^{T} c \mathrm{~d} T
$$

where $T_{\mathrm{m}}$ is the melting point $(\mathrm{K})$.

The melting fraction $f_{1}$ could be expressed as follows:

$$
f_{\mathbf{1}}= \begin{cases}0 & \text { if } T<T_{\mathrm{m}}, \text { (Solid) } \\ 1 & \text { if } T \geq T_{\mathrm{m}}, \text { (Liquid) }\end{cases}
$$

The density, specific heat, constant conductivity could be substituted in the one dimensional transient heat equation,

$c \frac{\partial T}{\partial t}=\frac{k}{\rho} \frac{\partial^{2} T}{\partial x^{2}}-L \frac{\partial f_{1}}{\partial t}$

where $k$ is the Conductivity $(\mathrm{W} / \mathrm{m} \cdot \mathrm{K})$.

\subsection{Combining model of the heat and moisture transfer with phase change process}

Substituting the heat transfer process of phase change into the whole heat 
transfer equilibrium equation, this model can calculate well with the heat and moisture transfer process of PCHCM.

The heat balance of wet building envelops can be expressed as follows:

$$
\frac{\partial H_{\mathrm{wet}}}{\partial T} \frac{\partial T}{\partial t}=\frac{\partial}{\partial x}\left(k_{\omega} \frac{\partial T}{\partial x}\right)+h_{\mathrm{v}} \frac{\partial}{\partial x}\left(\frac{\delta}{\mu} \frac{\partial P_{\mathrm{sat}}}{\partial x}\right)
$$

The specific enthalpy of dried building materials and contained moisture are included in the specific enthalpy $\left(\frac{\partial H_{w e t}}{\partial T}\right)$ :

$\frac{\partial H_{\text {wet }}}{\partial T}=\rho_{\text {dry }} c_{\text {dry }}+\omega c_{\text {p,vapor }}$

where $c_{\mathrm{p}, \text { vapor }}$ is the specific heat capacity of water vapor.

As the PCHCM mainly compose of MPCM and diatomite, the specific heat capacity of the dry material ( $c_{\text {dry }}$ ) varies with temperature fluctuations. The relationship between the specific heat capacity of dry material ( $\left.c_{\mathrm{dry}}\right)$ and temperature are explained by enthalpy method:

$\rho_{\text {dry }} c_{\text {dry }} \frac{\partial T}{\partial t}=\rho_{\text {dry }} \frac{\partial H_{\text {dry }}}{\partial t}$

Then plug the Eq. (10) and (11) into equation (9), the combined equation becomes:

$$
\rho_{\text {dry }} \frac{\partial H_{\text {dry }}}{\partial t}+\omega c_{\mathrm{p}, \text { vapor }} \frac{\partial T}{\partial t}=\frac{\partial}{\partial x}\left(k_{\omega} \frac{\partial T}{\partial x}\right)+h_{\mathrm{v}} \frac{\partial}{\partial x}\left(\frac{\delta}{\mu} \frac{\partial P_{\text {sat }}}{\partial x}\right)
$$

The function of the specific enthalpy of dried building material $\left(H_{\mathrm{wet}}\right)$ and temperature ( $T$ ) can be expressed as Eq. (5). Combining with the moisture transfer Eq. (1) and Eq. (3), Eq. (12) is the whole heat and moisture governing equations of HAMT-E model. The moisture content and temperature distributions of PCHCM 
could be calculated by the HAMT-E model. The workflow chart of the numerical calculation is shown in Fig. 2.

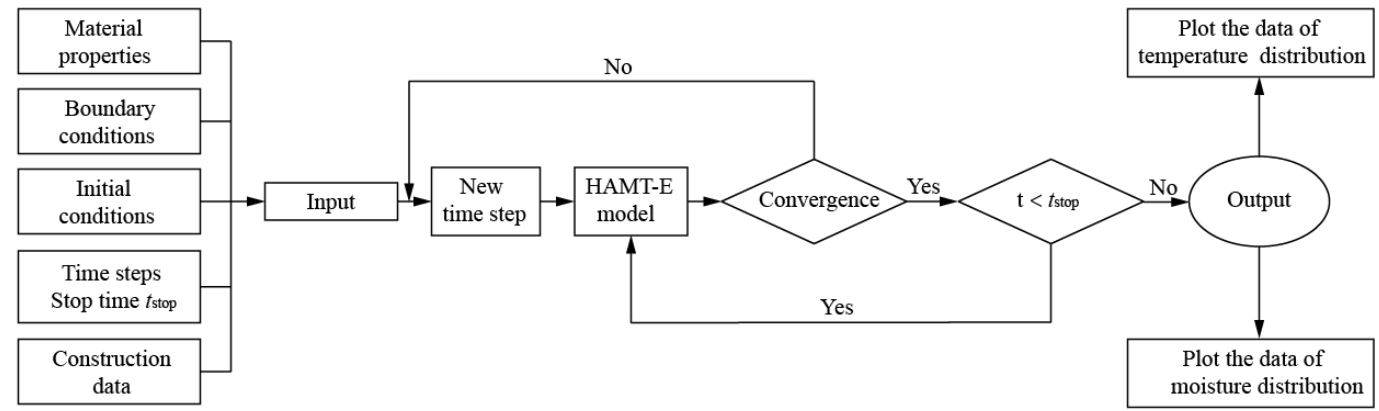

Fig. 2. Workflow chart of the numerical calculation.

\section{Validation}

The HAMT model [25, 31-32] and enthalpy method [30, 33-34] have already been validated by many researchers separately. In order to verify the coupled HAMT-E model, a test facility with the PCHCM layer was built in Nanjing University.

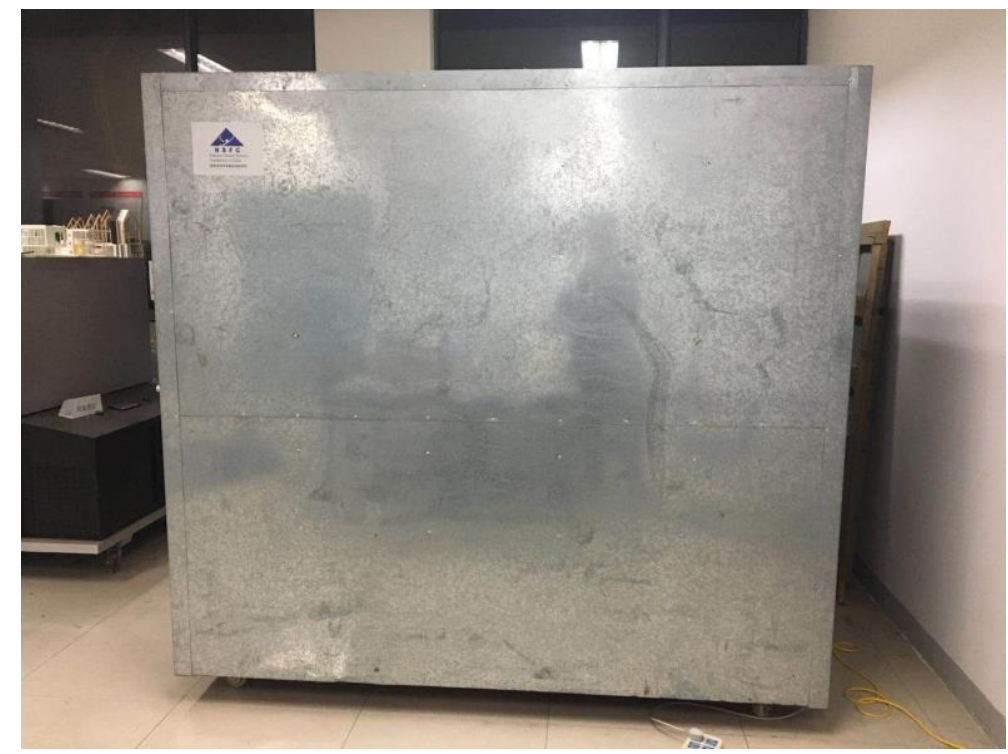

Fig. 3. Experimental cabin

As show in Fig. 3, the internal dimensions of the experimental cabin are $3 \mathrm{~m}$ 
(depth) $\times 2 \mathrm{~m}$ (width) $\times 2 \mathrm{~m}$ (height). The cabin are made of $30 \mathrm{~mm}$-thick wood boards and covered with an insulating material (thermal/humidity) on its four external sides. The $1 \mathrm{~m}$ (width) $\times 1.2 \mathrm{~m}$ (height) double-glazed window are equipped in the south wall. The interior floor is covered with a $2 \mathrm{~mm}$-thick PCHCM layer. The phase change temperature range of PCM is $25 \sim 27^{\circ} \mathrm{C}$. The tests are performed with a constant air change rate $(\mathrm{ACH})$ of $0.5 \mathrm{~h}^{-1}$. The experiment were conducted from July 1th to July 10th, 2017.

The temperature and relative humidity were measured both in the inside and outside space of the experimental cabin. The outdoor temperature and relative humidity were regarded as the input data for the HAMT-E model to calculate the instantaneous inside temperature and relative humidity. Fig. 4 and Fig. 5 show the comparison between the experimental and simulated results. The minor differences in temperature and humidity values between the calculated and experimental results are due to the following reasons: (1) different from the uniform simulation results, the experimental cabin has a non-uniform temperature and humidity distribution in practical experiments, while only the data of central point in the cabin were measured; (2) the actual heat transfer coefficients which depend on the real-time outside climate condition are variable values, while the surface heat transfer coefficients usually are constant in the simulation. Nevertheless, according to the coefficient of determination and mean square error (MSE), it can be seen that the relatively high coincide calculated results can be obtained with the HAMT-E model both in thermal and humidity aspect. The results show that the HAMT-E model is capable of simulating 
the whole building heat and moisture transfer.

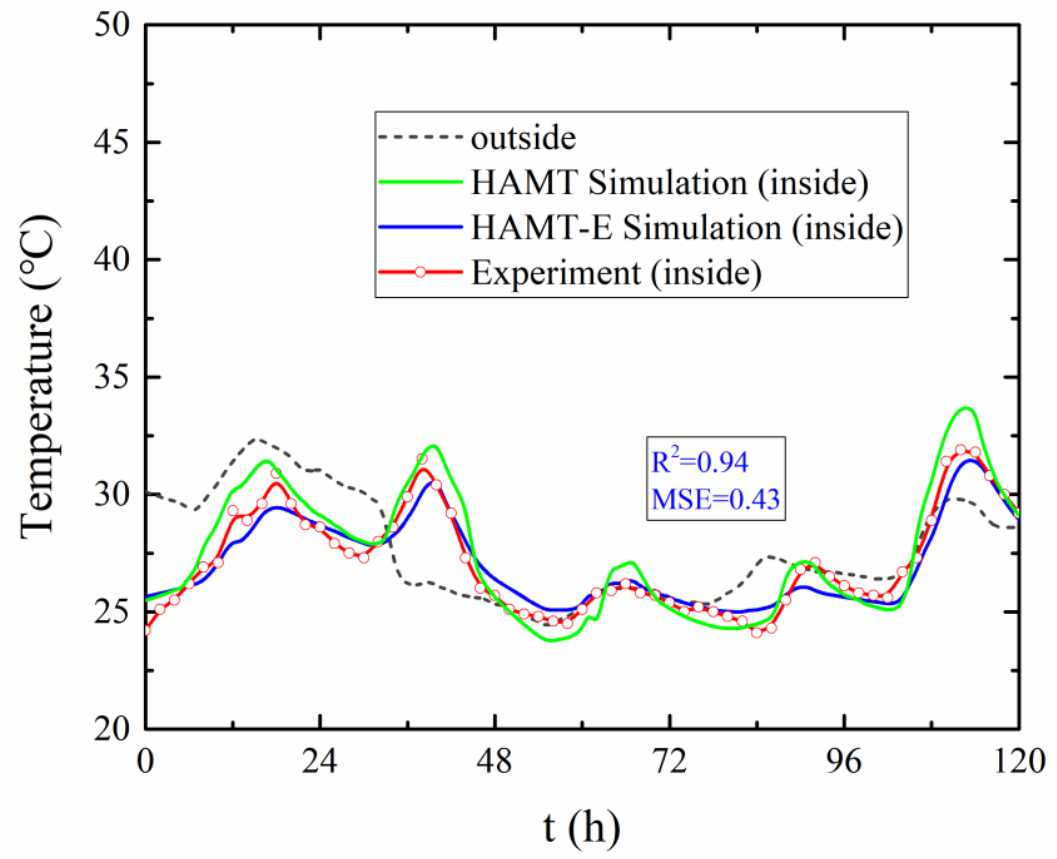

Fig. 4. The comparison of simulated indoor temperature with the measured data (Experimental cabin, July 4th-9th, 2017)

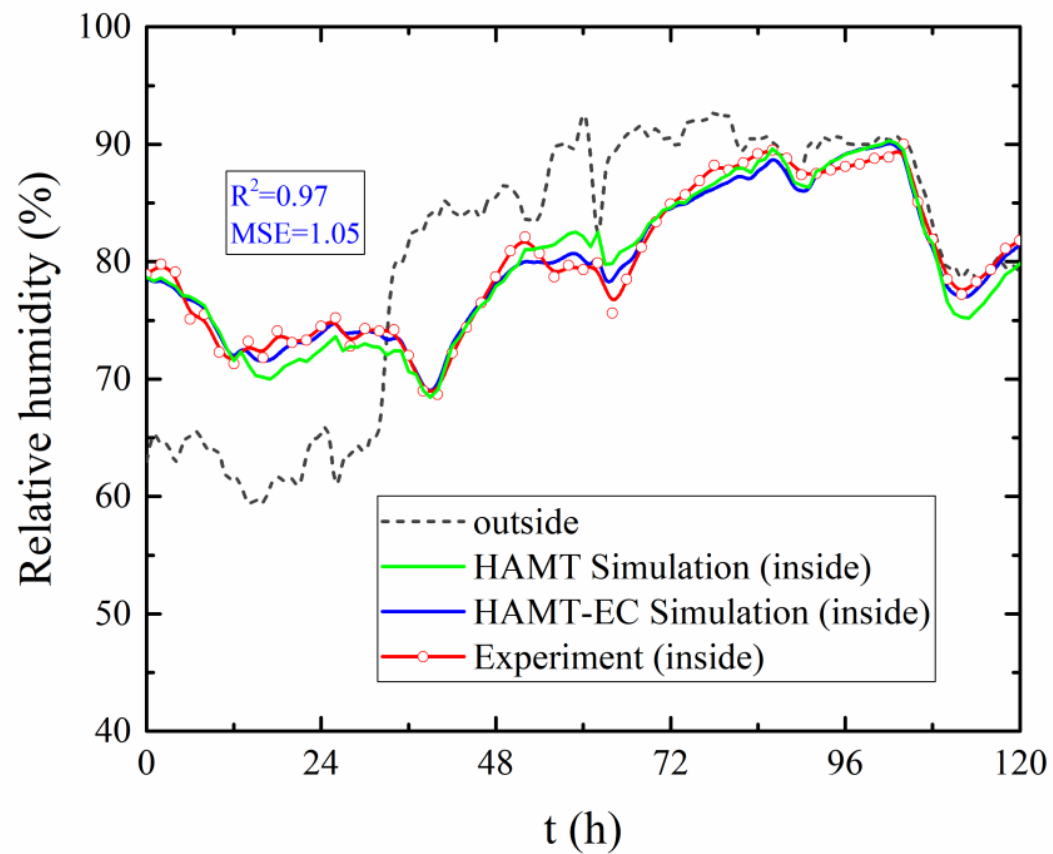

Fig. 5. The comparison of simulated indoor relative humidity with the measured data 


\section{Case study}

After being validated, HAMT-E model was applied to investigate the effect of PCHCM on indoor hygrothermal environment and building energy consumption under different climates. Four worldwide cities including Beijing, China (continental monsoon climate), Paris, France (temperate maritime climate), Atlanta, USA (subtropical semi-humid climate) and Guangzhou, China (subtropical humid climate) which characterized by typical urban climates were selected as boundary weather conditions for analysis. For accurate and typical results, The BESTEST base case building (shown in Fig. 6) from the IEA ECBCS Annex 21 was selected as the test building [35]. The BESTEST base case is assumed to be transferred to the four cities, where it serves as a typical office house. The room is occupied during the daytime from 9:00 am to 17:00 pm and unoccupied the rest of the day. The detailed physical parameters of different layers are listed as Table 4.

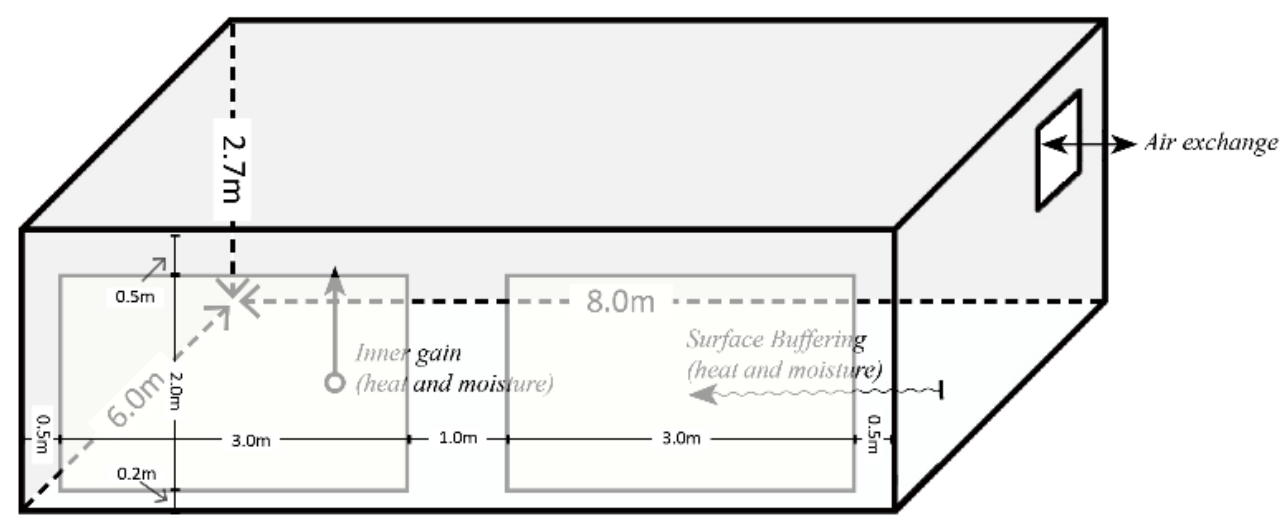

Fig. 6. The BESTEST base case building adopted in application examples 
In the research, diverse simulation cases including $0 \mathrm{~m}^{2}$ (Reference), $63.6 \mathrm{~m}^{2}$

(Case A.1: internal walls) and $159.6 \mathrm{~m}^{2}$ (Case A.2: internal walls, floor and ceiling) of

PCHCM which incorporated into interior surface were computed to analysis the application effect of PCHCM. The simulation settings and boundary conditions are shown in Table 5 as a office house.

\section{Table 4}

Physical parameters of different layers in building envelopes.

\begin{tabular}{|c|c|c|c|c|c|c|}
\hline Construction & Material & $\mathrm{d}(\mathrm{m})$ & $\begin{array}{l}\rho \\
\left(\mathrm{kg} / \mathrm{m}^{3}\right)\end{array}$ & $\begin{array}{l}\mathrm{c}_{\mathrm{p}} \\
(\mathrm{J} / \mathrm{kgK})\end{array}$ & $\begin{array}{l}K \\
(\mathrm{~W} / \mathrm{mK})\end{array}$ & $\begin{array}{l}U \\
\left(\mathrm{~W} / \mathrm{m}^{2} \mathrm{~K}\right)\end{array}$ \\
\hline \multirow{4}{*}{$\begin{array}{l}\text { Wall } \\
\text { (from outer layer to inner } \\
\text { layer) }\end{array}$} & Wooden board & 0.010 & 530 & 900 & 0.14 & \multirow[t]{4}{*}{0.474} \\
\hline & Rock wool board & 0.066 & 60 & 850 & 0.04 & \\
\hline & Concrete & 0.1 & 1400 & 1000 & 0.51 & \\
\hline & PCHCM layer & 0.02 & 650 & 975 & 0.85 & \\
\hline Roof & Cement panel & 0.012 & 1130 & 840 & 0.255 & \multirow[t]{3}{*}{0.307} \\
\hline (from outer layer to inner & Rock wool board & 0.122 & 60 & 850 & 0.04 & \\
\hline layer) & PCHCM layer & 0.02 & 650 & 975 & 0.85 & \\
\hline $\begin{array}{l}\text { Floor } \\
\text { (from outer layer to inner }\end{array}$ & $\begin{array}{l}\text { Thermal insulating } \\
\text { layer }\end{array}$ & 1 & 60 & 850 & 0.04 & \multirow[t]{2}{*}{0.04} \\
\hline layer) & PCHCM layer & 0.02 & 650 & 975 & 0.85 & \\
\hline Window & Double glazing unit & - & - & - & - & 1.99 \\
\hline
\end{tabular}

\section{Table 5}

Simulation settings and boundary conditions.

\begin{tabular}{|c|c|c|c|}
\hline \multirow{2}{*}{$\frac{\text { Conditions }}{\text { Case ID }}$} & \multicolumn{3}{|c|}{ Office case } \\
\hline & Reference & CaseA.1 & CaseA. 2 \\
\hline PCHCM area $\left(\mathrm{m}^{2}\right)$ & 0 & 63.6 & 159.6 \\
\hline Heat power $\left(\mathrm{W} / \mathrm{m}^{2}\right)$ & \multicolumn{3}{|c|}{15 (occupied period) } \\
\hline Moisture releasing rate $\left(\mathrm{g} / \mathrm{m}^{3} \mathrm{~h}\right)$ & \multicolumn{3}{|c|}{6 (occupied period) } \\
\hline Permissible room temperature range $\left({ }^{\circ} \mathrm{C}\right)$ & \multicolumn{3}{|c|}{ 18-26 (occupied period) } \\
\hline Permissible max relative humidity $(\mathrm{RH})$ & \multicolumn{3}{|c|}{$\leq 65 \%$ (occupied period) } \\
\hline Air change rate $(\mathrm{ACH})$ & \multicolumn{3}{|c|}{0.5 (2ACH in unoccupied time) } \\
\hline Air infiltration & \multicolumn{3}{|c|}{ No } \\
\hline Occupied period (h) & \multicolumn{3}{|c|}{ 09:00-17:00 } \\
\hline Unoccupied period & \multicolumn{3}{|c|}{ The rest of the day } \\
\hline
\end{tabular}




\section{Results and Discussion}

\subsection{Analysis of thermal and moisture performance}

In this section, the hygrothermal performance of an office building located in four different climates/cities worldwide (Beijing, Paris, Atlanta, and Guangzhou) was evaluated for a typical week in summer (August 1st-7th). Due to the limitation of the paper length, only the temperature and relative humidity curves of Paris and Guangzhou are presented.

Guangzhou has a subtropical climate with hot and humid summers. The south wind, which brings in hot and humid air, leads to high temperatures exceed $34{ }^{\circ} \mathrm{C}$ in the daytime and $26{ }^{\circ} \mathrm{C}$ at night with high relative humidity in the whole day. However, the hot and humid climate of Guangzhou is not representative of the temperate climate in Europe. Therefore, Paris, which has a temperate maritime climate with temperate summers, is also presented. The daily average temperature during the summer generally remain around $20^{\circ} \mathrm{C}$.

The BESTEST base case is assumed to be transferred to Guangzhou and Paris where it serves as a typical office house. Detailed simulation data for those two cases are presented in Table 5. The HVAC system only works during the occupied period. The quasi-steady conditions were obtained by the calculations of many years and the results were reported for the last year of calculation. To clearly demonstrate the application effect of PCHCM, simulated indoor temperature and relative humidity for one week (August 1st-7th) in summer are presented in Figs. 7-10. The outdoor 
temperature and relative conditions are also plotted in figures.

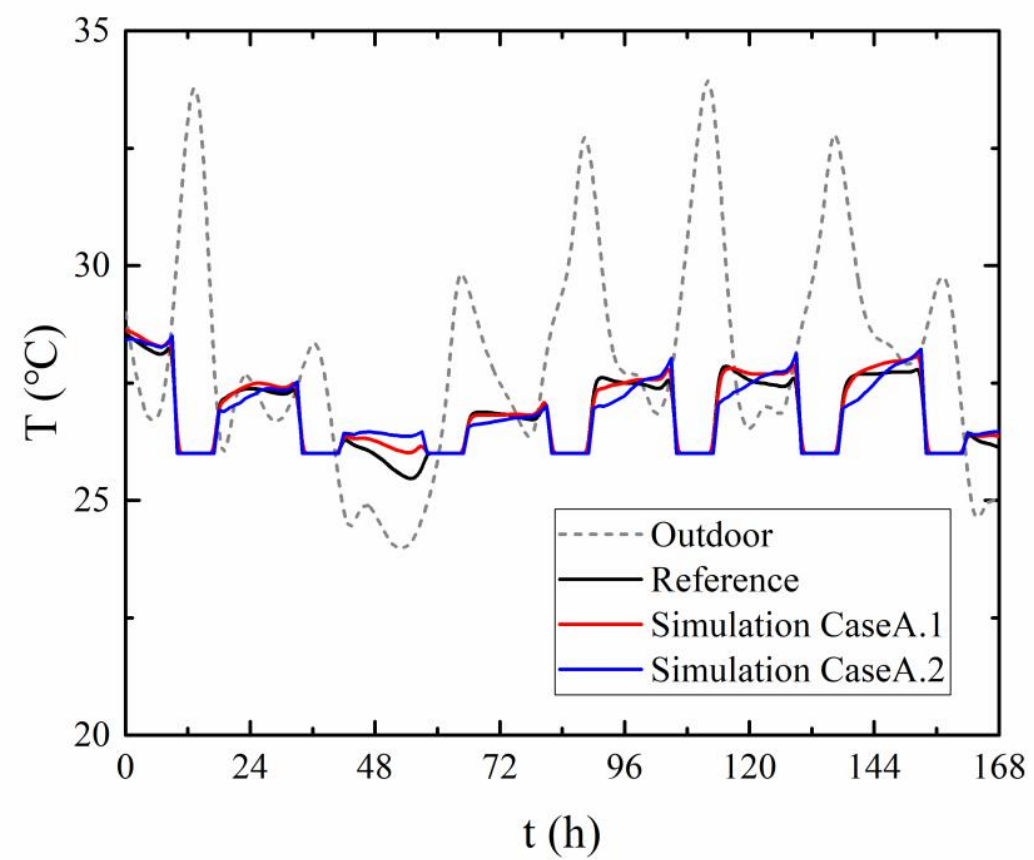

Fig. 7. Simulated indoor temperature (August 1st-7th) in Guangzhou

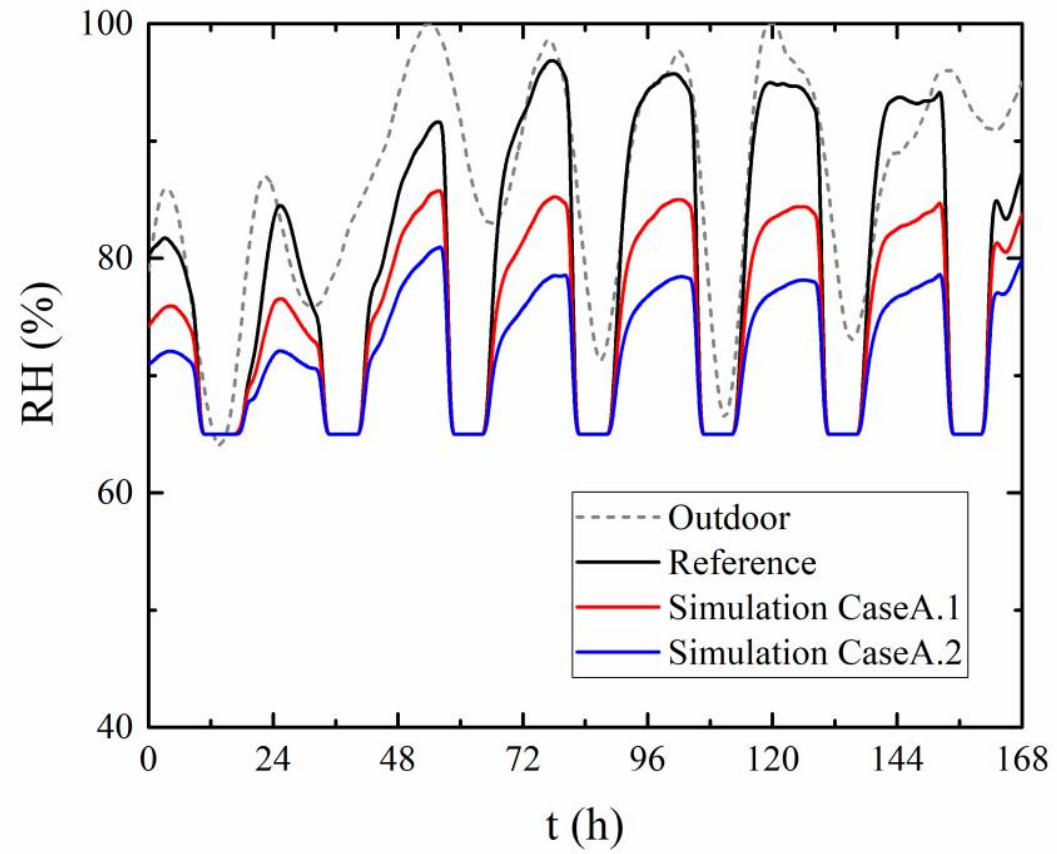

Fig. 8. Simulated indoor relative humidity (August 1st-7th) in Guangzhou 


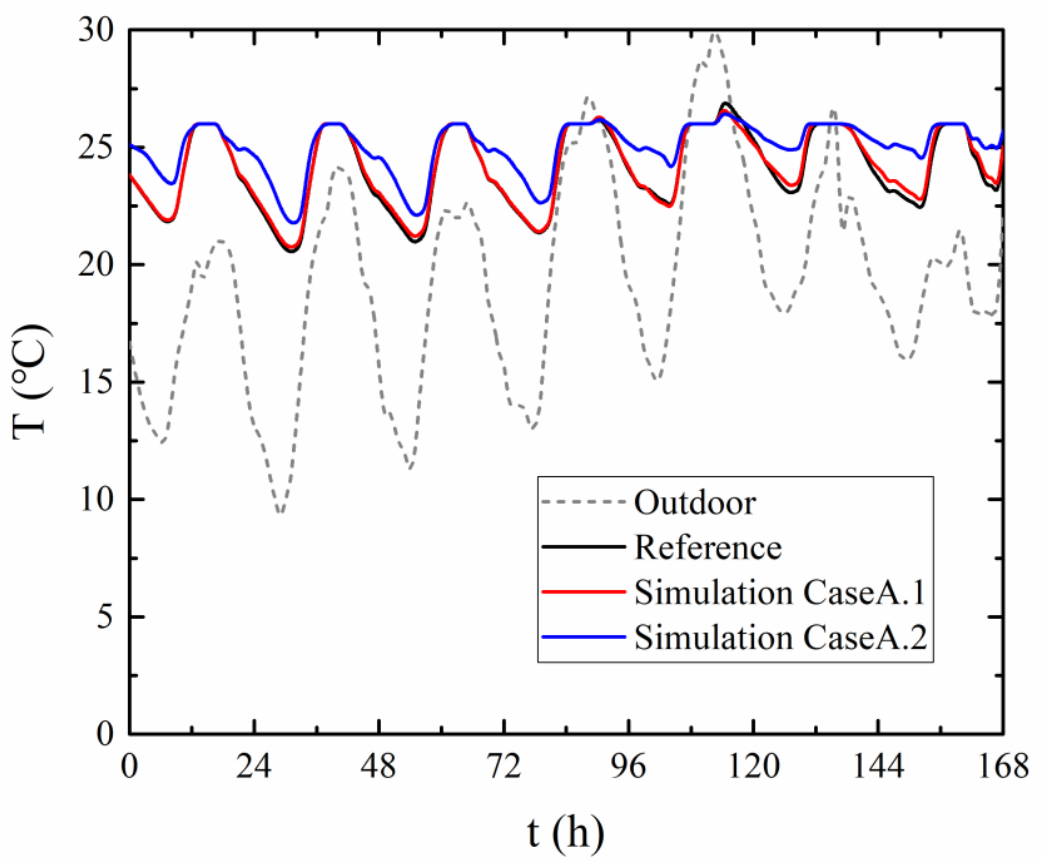

Fig. 9. Simulated indoor temperature (August 1st-7th) in Paris

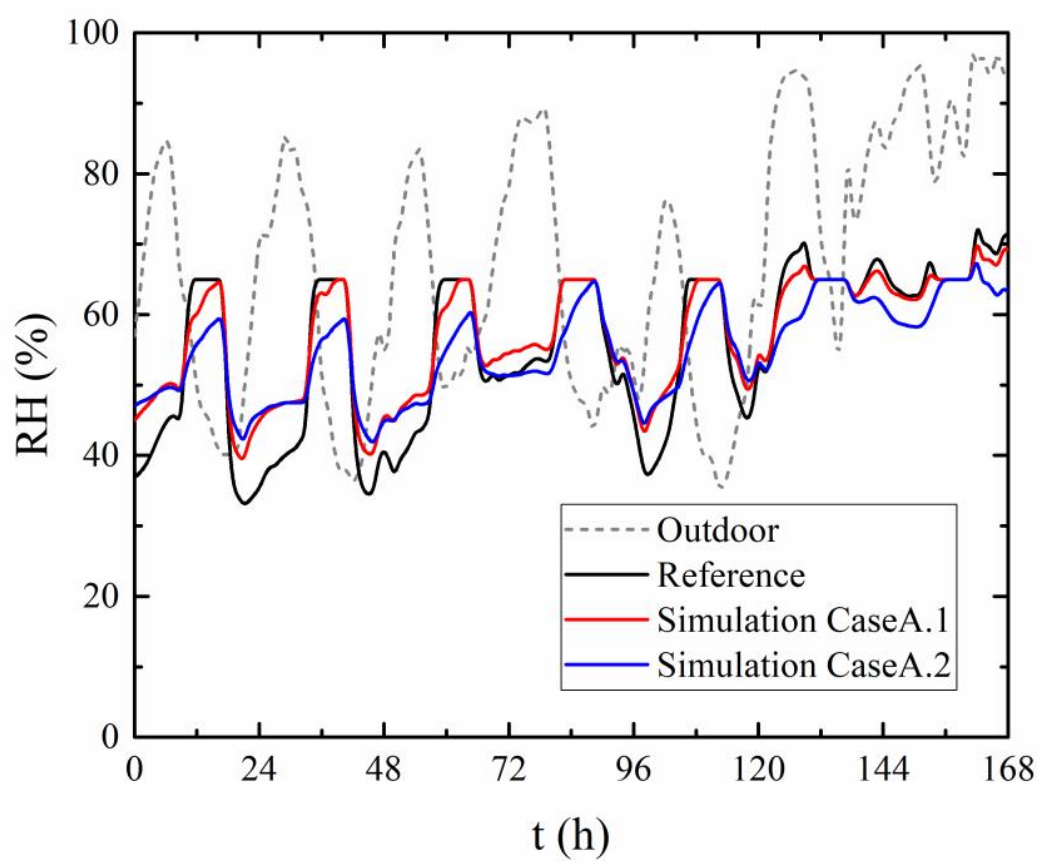

Fig. 10. Simulated indoor relative humidity (August 1st-7th) in Paris

From Fig. 7 and 9, it can be seen that cooling is needed for all 7 days in Guangzhou and Paris, which is caused by the combined effect of indoor heat 
production and outdoor radiant heat through windows. The indoor temperature during the night (un-occupied period) in reference room without PCHCM tends to be lower than that in Case A.1/A.2 which is covered with PCHCM layers. It demonstrates that the PCM components of PCHCM layer can reduce the peak cooling load of Case A.1/A.2 by absorbing heat when the surface temperature of the PCHCM layer is higher than the melting point of PCM in the daytime; and release the heat to the indoor air in the evening by night ventilation.

For hot and humid climates (Guangzhou case), the outdoor temperature is hot most time of a day (shown in Fig. 7), the performance of PCM has been largely limited. While in temperate climates (Paris case), the temperature difference between day and night is large, and therefore the PCM has a better performance in this climate. In the outdoor environment characterized by wide amplitude of temperature difference, the discharge process of stored heat at night can enhances the efficiency of daily cyclic procedure and reduces the cooling loads of air conditioning system. Detailed analysis of the energy performance will be discussed in the next section.

Fig. 8 and 10 show the simulated indoor relative humidity profiles for one week in summer in Guangzhou and Paris climates. Fig. 8 indicates that dehumidification is needed for all 7 days in Guangzhou case during the working period, while the indoor relative humidity in Case A.1/A.2 are much lower than that of the reference room during the unoccupied period. It means the PCHCM can moderate the indoor humidity fluctuation, and therefore reduce the energy demand for dehumidification especially during the unoccupied period. In this case, extra dehumidification is needed 
to reduce the moisture level in the reference room (without $\mathrm{PCHCM}$ ) during the unoccupied period, while there is no need for dehumidification for Case A.2 with PCHCM.

Fig. 10 shows the simulated indoor relative humidity profiles for Paris climate. There is a clear difference between the cases with and without PCHCM. For the reference room (without $\mathrm{PCHCM}$ ), dehumidification is needed for all 7 days. However, for the Case A.2 (with PCHCM), the indoor relative humidity is below $65 \%$ most time of the week, and therefore there is no need for dehumidification. A wide amplitude of outdoor relative humidity difference in Paris are favorable for regular adsorption and desorption process of PCHCM. Additionally, during the cooling process, the indoor enthalpy can be reduced by the decrement of indoor relative humidity that contributes to the reduction of the energy required to cool the office house.

The simulation was also repeated in Beijing and Atlanta. The results show that the PCHCM also has a moderate function on the indoor hygrothermal environment for those two kinds of climate situation. The impact on energy consumption will be discussed in the following section.

\subsection{Analysis of energy saving}

In a typical year, the annual energy consumption and efficiency of PCHCM applied on building interior surfaces are compared in Table 6. It is obvious that the energy saving quantity and efficiency tend to rise with the increase of PCHCM's area. 
It is illustrated that PCHCM could effectively moderate indoor hygrothermal environment and the notable energy saving effect could be obtained.

Noteworthy, higher energy saving efficiency can be achieved in Paris and Atlanta, which have a temperate climate characterized by the wide amplitude of outdoor hygrothermal difference. Guangzhou has a hot and humid climate. It usually has a high temperature and relative humidity condition in the whole day. The high outdoor air temperature restrains the exothermic process of melting of the PCM. Similarly, the high outdoor relative humidity prevents the desorption process of diatomite. Therefore, the residual heat and moisture in PCHCM could not be efficiently discharged by the outside hygrothermal environment. As a result, the cooling loads of air conditioning system cannot be reduced by the efficiency of daily cyclic procedure of PCHCM.

The values of energy saving efficiency strictly follow the conclusions mentioned above. For instance, it can be seen that the utilization of PCHCM achieves the high values of energy saving efficiency in summer typical week. In Beijing, Paris, Atlanta and Guangzhou, the energy saving efficiencies are $10.22 \%, 19.57 \%, 17.82 \%$ and $8.76 \%$ in CaseA.2, respectively. Additionally, the highest values of energy saving efficiency can be obtained in Paris with wide hygrothermal difference and the lowest can be obtained in Guangzhou with narrow hygrothermal difference, which can also be verified by the temperature and relative curves in Figs.6-9.

\section{Table 6}

Annual energy consumption and energy saving of different cities in office buildings (Beijing, Paris, Atlanta and Guangzhou). 


\begin{tabular}{lllll}
\hline \multirow{2}{*}{ City } & & \multicolumn{3}{c}{ Area of PCHCM } \\
\cline { 3 - 5 } & Load and efficiency & $0 \mathrm{~m}^{2}$ & $63.6 \mathrm{~m}^{2}$ & $159.6 \mathrm{~m}^{2}$ \\
& & $($ Reference) & (Case A.1) & (Case A.2) \\
\hline \multirow{2}{*}{ Beijing } & Total load $\left(\mathrm{kWh} / \mathrm{m}^{2} \mathrm{a}\right)$ & 78.52 & 75.41 & 70.49 \\
& Energy saving $(\%)$ & - & 3.96 & 10.22 \\
\multirow{3}{*}{ Paris } & Total load $\left(\mathrm{kWh} / \mathrm{m}^{2} \mathrm{a}\right)$ & 71.12 & 64.77 & 57.21 \\
& Energy saving $(\%)$ & - & 8.93 & 19.57 \\
\multirow{3}{*}{ Atlanta } & Total load $\left(\mathrm{kWh} / \mathrm{m}^{2} \mathrm{a}\right)$ & 71.13 & 67.52 & 58.45 \\
& Energy saving $(\%)$ & - & 5.07 & 17.82 \\
\multirow{2}{*}{ Guangzhou } & Total load $\left(\mathrm{kWh} / \mathrm{m}^{2} \mathrm{a}\right)$ & 104.57 & 102.09 & 95.41 \\
& Energy saving $(\%)$ & - & 2.37 & 8.76 \\
\hline
\end{tabular}

As the discharge process of stored heat and moisture in unoccupied period can enhance the efficiency of daily cyclic procedure, the adequate ventilation is recommended in Beijing, Paris and Atlanta that has a wide amplitude of temperature and humidity difference, to promote the exothermic and desorption process of PCHCM. The energy consumption and efficiency of different air change rates in Case A.2 of Paris and Atlanta are compared in Table 7. It is obviously that the larger air change rate increases the energy saving effect of PCHCM.

\section{Table 7}

Annual energy consumption and efficiency of different air change rates in CaseA.2 (Bejing, Paris and Atlanta).

\begin{tabular}{lllll}
\hline \multirow{2}{*}{ Occupancy schedule } & \multirow{2}{*}{ Load and efficiency } & \multicolumn{3}{c}{ Air change rate in unoccupied period } \\
& & $0.5 \mathrm{ACH}$ & $2 \mathrm{ACH}$ & 5ACH \\
\hline \multirow{2}{*}{ Beijing } & Total load $\left(\mathrm{kWh} / \mathrm{m}^{2} \mathrm{a}\right)$ & 73.95 & 70.49 & 66.10 \\
& Energy saving $(\%)$ & 5.82 & 10.22 & 15.81 \\
\multirow{2}{*}{ Paris } & Total load $\left(\mathrm{kWh} / \mathrm{m}^{2} \mathrm{a}\right)$ & 59.57 & 57.21 & 55.59 \\
& Energy saving $(\%)$ & 16.24 & 19.57 & 21.84 \\
\multirow{2}{*}{ Atlanta } & Total load $\left(\mathrm{kWh} / \mathrm{m}^{2}\right.$ a) & 64.13 & 58.45 & 51.85 \\
& Energy saving $(\%)$ & 9.84 & 17.82 & 27.10 \\
\hline
\end{tabular}

\section{Conclusions}

This study intends to investigate the application of PCHCM in office buildings as 
a passive method to reduce energy consumption and evaluates its impact on building energy performance under different climate conditions. In this paper, a model for analyzing the hygrothermal performance of the PCHCM is developed. The model is implemented in MATLAB-Simulink, and is validated by performing a series of experiments and validation tools. By using the model, the hygrothermal performance and energy saving effect of PCHCM in office building is analyzed.

The calculation model analyses the hygrothermal performance of PCHCM, which consist of the heat and moisture transfer process with phase change. The BESTEST base case is assumed to be in Beijing, China (continental monsoon climate), Paris, France (temperate maritime climate), Atlanta, USA (subtropical semi-humid climate) and Guangzhou, China (subtropical humid climate) where it serves as a typical office house. The results indicate that the PCHCM has a great impact on the hygrothermal performance in four cities. It can moderate the indoor hygrothermal variations and significantly reduce the peak/valley values of indoor temperature and relative humidity.

The research also indicates that the application of PCHCM has the potential to reduce the energy consumption of office buildings. Overall, the PCHCM presents a melting point of $25 \sim 27{ }^{\circ} \mathrm{C}$, which achieves the energy reduction of sensible heat in a summer typical week. Additionally, the porous structure of PCHCM enables the energy reduction of latent heat in moisture buffering process. From the analysis of energy saving, the overall energy saving potential of Paris with temperate maritime climate is found to be the best while the potential of energy reduction is limited in 
Guangzhou (located in subtropical humid climate) with high temperature and humidity all day long. Above all, the numerical results indicate that PCHCM is suitable for the areas that simultaneously manifest a wide amplitude of hygrothermal (temperature and humidity) difference. Naturally, larger air change rates of ventilation contribute to the better energy saving effect in those areas.

The model and the analysis are helpful for the application of PCHCM in different climate conditions.

\section{Acknowledgements}

The present study was financially supported by the national key project of the Ministry of Science and Technology of China on "Green Buildings and Building Industrialization" (Grant No. 2016YFC0700500), and the National Natural Science Foundation of China (Grant No. 51578278). 


\section{References}

[1] International Energy Agency. $\mathrm{CO}_{2}$ Emissions from fuel combustion: highlights (2012 ed.). Paris, France, 2012.

[2] Buildings and Climate Change, Summary for Decision-Makers, United Nations Environment Programme, 2009.

[3] I. Dincer, Energy and Environmental Impacts: Present and Future Perspectives, Energy Sources 20 (2007) 427-453.

[4] K. Menoufi, A. Castell, L. Navarro, G. Pérez, D. Boer, L.F. Cabeza, Evaluation of the environmental impact of experimental cubicles using Life Cycle Assessment: a highlight on the manufacturing phase, Appl. Energy 92 (2012) 534-544.

[5] K.O. Lee, M.A. Medina, E. Raith, X. Sun, Assessing the integration of a thin phase change material (PCM) layer in a office building wall for heat transfer reduction and management, Appl. Energy 137 (2015) 699-706

[6] N. Soares, J.J. Costa, A.R. Gaspar, P. Santos, Review of passive PCM latent heat thermal energy storage systems towards buildings' energy efficiency, Energy Build. 59 (2013) 82-103.

[7] Cabeza L F, Castellon C, Nogues M, et al. Use of microencapsulated PCM in concrete walls for energy savings[J]. Energy and Buildings, 2007, 39(2): 113-119.

[8] P. Moreno, C. Solé, A. Castell, L.F. Cabeza, The use of phase change materials in 
domestic heat pump and air-conditioning systems for short term storage: A review, Renew. Sustain. Energy Rev. 39 (2014) 1-13.

[9] S. Sadineni, S. Madala, R. Boehm, Passive building energy savings: A review of building envelope components, Renewable and Sustainable Energy Reviews 15 (2011) $3617-3631$

[10] Z. Chen, M. Qin, J. Yang, Synthesis and characteristics of hygroscopic phase change material: Composite microencapsulated phase change material (MPCM) and diatomite, Energy and Buildings 106 (2015) 175-182.

[11] C. Barreneche, M.E. Navarro, I.a. Fernández, L.F. Cabeza, Improvement of the thermal inertia of building materials incorporating PCM. Evaluation in the macroscale, Appl. Energy 109 (2013) 428-432.

[12] G. Evola, L. Marletta, F. Sicurella, A methodology for investigating the effectiveness of PCM wallboards for summer thermal comfort in buildings, Build. Environ. 59 (2013) 517-527.

[13] M.M. Farid, A. Sherrif, 16 - Phase change materials for energy storage and thermal comfort in buildings, in: M.R. Hall (Ed.), Materials for Energy Efficiency and Thermal Comfort in Buildings, Woodhead Publishing, United Kingdom, 2010, pp. 384-398.

[14] I. Andersen, J. Korsgaard, Asthma and the indoor environment: assessment of the health implications of high indoor air humidity, Environment International 12 (1984) $121-127$

[15] J. Toftum, A.S. Jørgensen, P.O. Fanger, Upper limits of air humidity for 
preventing warm respiratory discomfort, Energy and Buildings 28 (1998) 15-23.

[16] Zhang H, Yoshino H, Hasegawa K. Assessing the moisture buffering performance of hygroscopic material by using experimental method $[\mathrm{J}]$. Building and environment, 2012, 48: 27-34.

[17] Osanyintola O F, Simonson C J. Moisture buffering capacity of hygroscopic building materials: Experimental facilities and energy impact[J]. Energy and Buildings, 2006, 38(10): 1270-1282.

[18] Rode C, Peuhkuri R H, Mortensen L H, et al. Moisture buffering of building materials[J]. 2005.

[19] Woloszyn M, Kalamees T, Abadie M O, et al. The effect of combining a relative-humidity-sensitive ventilation system with the moisture-buffering capacity of materials on indoor climate and energy efficiency of buildings $[\mathrm{J}]$. Building and Environment, 2009, 44(3): 515-524.

[20] Z. Chen, L. Cao, G. Fang, F. Shan, Synthesis and characterization of microencapsulated paraffin microcapsules as shape-stabilized thermal energy storage materials, Nanosc. Microsc. Thermophys. Eng. 17 (2013) 112-123.

[21] Z. Chen, D. Su, M. Qin, G. Fang, Preparation and characteristics of composite phase change material (CPCM) with $\mathrm{SiO}_{2}$ and diatomite as endothermal-hydroscopic material, Energy and Buildings 86 (2015) 1-6.

[22] Luikov AW (1966) Heat and mass transfer in capillary-porous bodies. Pergamon Press, Oxford.

[23] Philip JR, De Vries DA (1957) Trans Am Geophys Union 38(2):222. 
[24] H. Künzel, Simultaneous heat and moisture transport in building components. Ph.D. Thesis, Fraunhofer Institute of Building Physics, Fraunhofer IRB, Germany, 1995.

[25] M. Qin, R. Belarbi, A. Aït-Mokhtar, L.-O. Nilsson, Coupled heat and moisture transfer in multi-layer building materials, Construction and Building Materials, 23 (2009) 967-975.

[26] M. Qin, R. Belarbi, Development of an analytical method for simultaneous heat and moisture transfer in building materials utilizing transfer function method, Journal of Materials in Civil Engineering, 17 (2005) 492-497.

[27] Voller V R, Cross M, Markatos N C. An enthalpy method for convection/diffusion phase change[J]. International journal for numerical methods in engineering, 1987, 24(1): 271-284.

[28] Swaminathan C R, Voller V R. On the enthalpy method[J]. International Journal of Numerical Methods for Heat \& Fluid Flow, 1993, 3(3): 233-244.

[29] C. Rode, R. Peuhkuri, B. Time, K. Svenberg, T. Ojanen, Moisture buffer value of buildings, J. ASTM Int. 4 (2007) 1-12.

[30] Sharma A, Sharma S D, Buddhi D, et al. Effect of thermo physical properties of heat exchanger material on the performance of latent heat storage system using an enthalpy method[J]. International Journal of Energy Research, 2006, 30(3): 191-201.

[31] Thomas H R, He Y. Analysis of coupled heat, moisture and air transfer in a deformable unsaturated soil[J]. Geotechnique, 1995, 45(4): 677-689.

[32] Tenchev R T, Li L Y, Purkiss J A. Finite element analysis of coupled heat and 
moisture transfer in concrete subjected to fire[J]. Numerical Heat Transfer: Part A: Applications, 2001, 39(7): 685-710.

[33] Bellecci C, Conti M. Phase change thermal storage: transient behaviour analysis of a solar receiver/storage module using the enthalpy method[J]. International Journal of Heat and Mass Transfer, 1993, 36(8): 2157-2163.

[34] Tabares-Velasco P C, Christensen C, Bianchi M. Verification and validation of EnergyPlus phase change material model for opaque wall assemblies[J]. Building and Environment, 2012, 54: 186-196.

[35] H. Zhang, H. Yoshino, K. Hasegawa, J. Liu, W. Zhang, H. Xuan, Practical moisture buffering effect of three hygroscopic materials in real-world conditions, Energy and Buildings 139 (2017), 214-223. 


\section{List of Figure captions}

Fig. 1. SEM photographs of the MPCM (a) and diatomite (b)

Fig. 2. Workflow chart of the numerical calculation.

Fig. 3. Experimental cabin

Fig. 4. The comparison of simulated indoor temperature with the measured data (Experimental cabin, July 4th-9th, 2017)

Fig. 5. The comparison of simulated indoor relative humidity with the measured data (Experimental cabin, July 4th-9th, 2017)

Fig. 6. The BESTEST base case building adopted in application examples

Fig. 7. Simulated indoor temperature (August 1st-7th) in Guangzhou

Fig. 8. Simulated indoor relative humidity (August 1st-7th) in Guangzhou

Fig. 9. Simulated indoor temperature (August 1st-7th) in Paris

Fig. 10. Simulated indoor relative humidity (August 1st-7th) in Paris 


\section{List of Tables captions}

Table 1. Physical property parameters of PCHCM.

Table 2. Thermal performance data of the PCM, MPCM and PCHCM.

Table 3. Moisture performance data of the PCHCM, gypsum, wood and diatomite.

Table 4. Physical parameters of different layers in building envelopes.

Table 5. Simulation settings and boundary conditions.

Table 6. Energy consumption and energy saving of different cities in office buildings (Beijing, Paris, Atlanta and Guangzhou).

Table 7. Energy consumption and efficiency of different air change rates in CaseA.2 (Bejing, Paris and Atlanta). 